\title{
Topographic Mapping between Basal Forebrain Cholinergic Neurons and the Medial Prefrontal Cortex in Mice
}

\author{
Bernard Bloem, ${ }^{1 *}$ Luc Schoppink, ${ }^{2 *}$ Diana C. Rotaru, ${ }^{1}$ Amu Faiz, ${ }^{1}$ Patrick Hendriks, ${ }^{1}$ Huibert D. Mansvelder, ${ }^{1}$ \\ Wilma D.J. van de Berg, ${ }^{2}$ and Floris G. Wouterlood ${ }^{2}$ \\ ${ }^{1}$ Department of Integrative Neurophysiology, Center for Neurogenomics and Cognitive Research, Neuroscience Campus Amsterdam, Vrije University, 1081 \\ HV Amsterdam, The Netherlands, and 2Department of Anatomy and Neurosciences, Vrije University Medical Center, Neuroscience Campus Amsterdam, \\ 1007 MB Amsterdam, The Netherlands
}

\begin{abstract}
The basal forebrain cholinergic innervation of the medial prefrontal cortex (mPFC) is crucial for cognitive performance. However, little is known about the organization of connectivity between the basal forebrain and the MPFC in the mouse. Using focal virus injections inducing Cre-dependent enhanced yellow fluorescent protein expression in ChAT-IRES-Cre mice, we tested the hypothesis that there is a topographic mapping between the basal forebrain cholinergic neurons and their axonal projections to the mPFC. We found that ascending cholinergic fibers to the MPFC follow four pathways and that cholinergic neurons take these routes depending on their location in the basal forebrain. In addition, a general mapping pattern was observed in which the position of cholinergic neurons measured along a rostral to caudal extent in the basal forebrain correlated with a ventral to dorsal and a rostral to caudal shift of cholinergic fiber distribution in MPFC. Finally, we found that neurons in the rostral and caudal parts of the basal forebrain differentially innervate the superficial and deep layers of the ventral regions of the mPFC. Thus, a frontocaudal organization of the cholinergic system exists in which distinct $\mathrm{mPFC}$ areas and cortical layers are targeted depending on the location of the cholinergic neuron in the basal forebrain.
\end{abstract}

Key words: basal forebrain; ChAT-IRES-Cre mouse; cholinergic system; prefrontal cortex; stereology; tracing

\section{Introduction}

Cholinergic modulation of the medial prefrontal cortex (mPFC) is crucial for various aspects of cognitive and executive behavior, including attention and working memory (Sarter and Bruno, 2000; Granon et al., 2003; Dalley et al., 2004; Parikh et al., 2007; Hasselmo and Sarter, 2011; Klinkenberg et al., 2011; Picciotto et al., 2012; Howe et al., 2013; Wallace and Bertrand, 2013). Although local cholinergic interneurons exist (Eckenstein and Baughman, 1984; Houser et al., 1985; Parnavelas et al., 1986; Mechawar et al., 2000), the main cholinergic innervation originates in the basal forebrain (Butcher and Woolf, 2004). To understand how acetylcholine modulates the mPFC, detailed knowledge of the pattern of cholinergic innervation and the differences in innervation between different $\mathrm{mPFC}$ regions and lay-

\footnotetext{
Received July 22, 2014; revised Sept. 16, 2014; accepted 0ct. 13, 2014.

Author contributions: B.B., D.R., H.D.M., W.D.v.d.B., and F.G.W. designed research; B.B., L.S., D.R., A.F., P.H., and F.G.W. performed research; L.S., W.D.v.d.B., and F.G.W. analyzed data; B.B., L.S., and F.G.W. wrote the paper. B. B and L.S. contributed equally and share responsibility as first author.

H.D.M. received funding for this work from European Research Council Starting Grant "BrainSignals," the Dutch Fund for Economic Structure Reinforcement (Grant 0908, "NeuroBasic PharmaPhenomics Project"), and European Union 7th Framework Programme (HEALTH-F2-2009-242167 "SynSys"). We thank Dr. Karl Deisseroth (Department of Bioengineering, Stanford University, Stanford, (A) for kindly providing samples of AAV, Evelien HuismanTimmermans for assisting us with stereological procedures, and Dr. Henri van de Werd for help with the parcellation of the medial prefrontal cortex.

*B.B and L.S. contributed equally to this work and share responsibility as co-first authors.

The authors declare no competing financial interests.

Correspondence should be addressed to Dr. Floris G. Wouterlood, Vrije University Medical Center, MF-G-136, P.0. Box 7057, 1007 MB Amsterdam, The Netherlands. E-mail: fg.wouterlood@vumc.nl.

DOI:10.1523/JNEUROSCI.3011-14.2014

Copyright $\odot 2014$ the authors $\quad 0270-6474 / 14 / 3416234-13 \$ 15.00 / 0$
}

ers is necessary. Despite many studies on the relation between different nuclei and locations in the basal forebrain and their projection areas, it is still unknown how specific the projections are and how exactly different regions in the basal forebrain map on their cortical targets. We test the hypothesis that different $\mathrm{mPFC}$ regions and layers receive inputs from distinct parts of the basal forebrain.

Combining retrograde fluorescent neuroanatomical tracing and antibody staining against choline acetyltransferase (ChAT; Cozzari and Hartman, 1980; Kimura et al., 1980; Eckenstein et al., 1981; Levey and Wainer, 1982) and vesicular acetylcholine transporter (Weihe et al., 1996), it was found that small groups of cholinergic basal forebrain neurons innervate rather large but discrete cortical areas (Bigl et al., 1982; Price and Stern, 1983; Rye et al., 1984; Butcher, 1995; Chandler and Waterhouse, 2012; Chandler et al., 2013). However, because of inherent limitations, classical neuroanatomical tracing and immunohistochemical methods are unable to test unequivocally whether a mapping exists in the connections from the basal forebrain to the mPFC (Zaborszky et al., 2013). First, retrograde tracers accumulate in neurons that project to that cortical area regardless of their neurotransmitter. Second, axonal projection densities of retrogradely labeled neurons cannot be unambiguously determined. Third, antibody stainings do not differentiate between the origin of cholinergic fibers. Finally, because cholinergic neurons in the basal forebrain are scattered among neurons with different neurochemical identities, injections with anterograde neuroanatomical tracers (Luiten et al., 1987; Gaykema et al., 1990) result in 
labeling of chemically diverse neurons. As a consequence, verification is mandatory, via high-resolution immunohistochemistry, of the identity of the neurotransmitter expressed by neuroanatomically traced fibers (Lanciego and Wouterlood, 2011).

To circumvent these limitations, we virally expressed enhanced yellow fluorescent protein (eYFP) in cholinergic neurons of ChAT-Cre mice at distinct locations in the basal forebrain and tested whether there is a topographic mapping between cholinergic neurons in the basal forebrain and different areas and layers of the mPFC. Using stereological methods, we found a frontalcaudal gradient in the mapping of the cholinergic projections with rostral neurons in the basal forebrain innervating predominantly rostral and ventral mPFC areas and caudolateral neurons in the basal forebrain preferentially innervating the dorsal and caudal mPFC regions. Furthermore, different areas of the basal forebrain send projections through four different pathways that differentially target deep and superficial layers of the mPFC.

\section{Materials and Methods}

Mice

Knock-in recombinant mice (The Jackson Laboratory strain B6;129S6Chat ${ }^{\mathrm{tml} \text { (cre)Lowl} / J) ~ o f ~ e i t h e r ~ s e x ~ w e r e ~ u s e d . ~ I n ~ t h e s e ~ m i c e, ~ C r e-~}$ recombinase expression is controlled via an IRES-Cre sequence inserted in the genome downstream of the ChAT gene stop codon. Expression of the ChAT gene is unaffected in these mice. In total, nine adult, knock-in mice ( 22 weeks of age; body weight, $\sim 30 \mathrm{~g}$ ) were used. All experiments were performed according to the ethical and legal guidelines and directives set by the Dutch Government and by University and European Community regulations on animal well being and approved by the Vrije University Medical Center ethical committee for animal welfare. The smallest number of animals possible was used to substantiate our findings.

\section{Injection of virus vector}

Mice were anesthetized with $2 \%$ isoflurane and mounted in a stereotaxic frame. The skull was exposed, the periosteum anesthetized with lidocaine, and a hole drilled to lower a micropipette with the virus vector to the appropriate stereotaxic coordinates (coordinates according to the mouse brain atlas by Paxinos and Franklin, 2001), after which the isoflurane was lowered to $1.5 \%$. In each mouse, a single injection of virus was placed at a preselected locus in the cholinergic basal forebrain $[0.5 \mu \mathrm{l}$ of virus solution; adeno-associated virus 2 (AAV2); EF1 $\alpha$-DIO-EFYPWPRE-pA; gift from Dr. Karl Deisseroth, Department of Bioengineering, Stanford University, Stanford, CA]. Virus was delivered via a stainless steel cannula (type 304; $200 \mu \mathrm{m}$ diameter; Phymep) attached to a CMA 400 syringe pump (Phymep), during $5 \mathrm{~min}$ (flow, $100 \mathrm{nl} / \mathrm{min}$ ). The needle was left in situ for $7 \mathrm{~min}$ and slowly stepwise retracted. Suturing the skin over the wound completed surgery, and the animal was allowed to recover.

\section{Immunofluorescence staining procedure}

Five weeks after surgery, the mice were killed and perfused. They were anesthetized with $2 \%$ isoflurane, followed by $1.6 \mathrm{~g} / \mathrm{kg}$ urethane and subsequently transcardially perfused at room temperature with $\sim 50 \mathrm{ml}$ of PBS (in mm: $200 \mathrm{KH}_{2} \mathrm{PO}_{4}, 400 \mathrm{~K}_{2} \mathrm{HPO}_{4}$, and $1.500 \mathrm{NaCl}$, pH 7.4) to flush out erythrocytes, followed immediately by fixative: $4 \%$ freshly depolymerized paraformaldehyde in PBS $(50 \mathrm{ml})$. Thereafter, the brains were recovered and postfixed for $24 \mathrm{~h}$ in the fixative and stored in PBS at $4^{\circ} \mathrm{C}$ before slicing into four series of $50-\mu \mathrm{m}$-thick frontal sections using a vibrating microtome (HR2; Sigmann Elektronik). Sections were stored in PBS in a refrigerator, with preservative added $\left(0.02 \% \mathrm{NaN}_{3}\right)$. Sections were rinsed three times for $10 \mathrm{~min}$ with TBS-TX buffer [50 mM Tris, $8.75 \% \mathrm{NaCl}$, and $0.2-0.3 \%$ Triton $\mathrm{X}-100$, pH 7.8 (Triton is a trademark of Sigma) ] and incubated under continuous gentle agitation. The immunofluorescence procedure was as follows.

Series 1 . Sections stayed for $1 \mathrm{~h}$ at room temperature in blocking solution $[2.5 \%$ bovine serum albumin and $5 \%$ normal goat serum in TBS-TX
$(0.2 \%)]$, followed by overnight incubation at $4^{\circ} \mathrm{C}$ (refrigerator) in a mixture consisting of 1:1000 anti-NeuN (mouse; catalog \#MAB377; MerckMillipore) mixed with 1:1000 anti-green fluorescent protein (GFP; rabbit; catalog \#AB3080; Merck-Millipore) in blocking solution in TBS.

Series 2. Sections stayed $1 \mathrm{~h}$ at room temperature in blocking solution (5\% normal donkey serum in TBS-TX) and next overnight in a refrigerator in 1:200 anti-ChAT (goat; catalog \#AB144P; Merck-Millipore) in TBS with $10 \%$ normal donkey serum added.

The next morning, the sections were rinsed four times for $10 \mathrm{~min}$ in TBS and subsequently incubated for $2 \mathrm{~h}$ with the secondary antibodies. Sections used in series 1 were incubated with either 1:400 goat antimouse Cy3 (Jackson ImmunoResearch) or with a mixture of 1:400 goat anti-mouse Alexa Fluor 594 (Invitrogen) and 1:400 goat anti-rabbit Alexa Fluor 488 (Invitrogen) in TBS, whereas in series 2, we incubated with 1:400 donkey-anti goat Alexa Fluor 594 (Invitrogen) in TBS. Series 1 resulted in NeuN-only stained sections with native eYFP expression and, in NeuN-stained sections, with immunofluorescence eYFP expression. Series 2 resulted in ChAT-stained sections with native eYFP expression.

After the incubations, the sections were rinsed in TBS, mounted on slides, and wet coverslipped immediately in an anti-fading mounting medium [ $2.4 \mathrm{~g}$ of Mowiol 4-44 (Clariant) and $6.0 \mathrm{~g}$ of glycerin (Fluka) in $18 \mathrm{ml}$ of $100 \mathrm{~mm}$ Tris, $\mathrm{pH}$ 8.5]. The NeuN-GFP double-immunostained sections were stereologically analyzed. In addition, NeuN-GFP and ChAT-immunostained sections were investigated with confocal laser scanning microscopy (CLSM). Prefrontal cortical areas in the mouse were identified and delineated in the NeuN-immunofluorescence material using cytological criteria published by Van de Werd et al. (2010). Neurons expressing eYFP are further called eYFP-positive neurons.

\section{Antibody characterization}

Anti-NeuN (mouse; catalog \#MAB377; Merck-Millipore) has been generated from clone $\mathrm{AB} 60$. This clone was generated and fully characterized by Mullen et al. (1992). Anti-GFP (rabbit; catalog \#AB3080; MerckMillipore) was generated against highly purified native GFP from Aequorea victoria. It is reactive with GFP and eYFP from both native and recombinant sources. This particular antibody has been purified to suppress cross-reactivity with non-GFP antigens (e.g., Escherichia coli). A full description and characterization has been published by Tamamaki et al. (2000). Anti-ChAT (goat; catalog \#AB144P, lot JC1668317; MerckMillipore) is a $70-74 \mathrm{kDa}$ affinity-purified polyclonal antibody raised against human placental enzyme. It has been characterized previously (Shiromani et al., 1987), and it has been evaluated by the manufacturer with Western blot analysis on mouse brain lysates. The secondary, fluorochromated antibodies were tested in our own laboratory according to the extensive omission, double-staining, and cross-staining control procedures published previously (Wouterlood et al., 1998).

\section{Stereological analysis}

Sections were inserted in a Leica DM-R epifluorescence microscope equipped with Leica filter cubes I3 ("green" fluorescence) and N2.1 ("red" fluorescence) and with a MicoFire digital camera (model S99808; Optotronics). Movements in the $x$ and $y$ directions were controlled via a MAC 2000 motorized stage controller (Ludl Electronic Products); movements along the $z$-axis were recorded with a resolution of $0.5 \mu \mathrm{m}$ by a Heidenhain MT12 microcator (Heidenhahn). $x, y, z$ microscope stage data were recorded by a computer running Stereo Investigator software (version 10.50; MicroBrightField). In brief, we outlined at $25 \times$ magnification via $\mathrm{N} 2.1$ cube filtering the $\mathrm{MPFC}$ and identified within $\mathrm{mPFC}$ the prelimbic (PL), infralimbic (IL), dorsal (ACd) and ventral (ACv) anterior cingulate, and frontal 2 (Fr2) subdivisions according to Van de Werd et al. (2010) (see Fig. 4). Then we switched to I3 cube filtering and counted at high magnification (100× oil-immersion objective) eYFP fiber lengths in 3D spherical counting frames in systematic random samples in each mPFC subdivision, using the "Space Ball" probe and workflow of Stereo Investigator (version 10.5). The Space Ball probe is designed to estimate the total length of neuronal fibers independent of their orientation in a region of interest. The concept and algorithms behind Space Balls have been published previously (Mouton et al., 2002; Schmitz and Hof, 2005). Briefly, the Space Ball method places 3D virtual 
spheres or hemispheres in a region of interest using a systematic random sampling approach. The investigator then counts the number of intersections between eYFP-positive fibers and the boundary of the $3 \mathrm{D}$ virtual (hemi)spheres. Counts that are at the bottom edge of the hemisphere are counted as $1 / 2$ in the results. Based on the number of intersections and volume of the region, the total length of eYFP-positive fibers and fiber length density (FLD) in the region of interest are calculated. The Space Balls are placed in a systematic random order throughout the region of interest to ensure that all eYFP-positive fibers had equal probability to be counted.

eYFP-positive fibers were relatively easy to discriminate from the background signal and possible artifacts. Because of the low density of eYFP-positive fibers in certain areas, we decided to use a hemispheric probe to increase the probe volume and, because the cortical layers of the mouse brain are too thin compared with the size of the Space Ball probe, we refrained from taking samples from cortical layers. Before the quantification, at least five measurements for thickness were made in each subregion to provide an estimate for the mounted post-processing thickness. Mean mounted thickness was estimated by averaging the samples taken from all the used sections for each animal. The mean postprocessing thickness was $31.6 \pm 2.7 \mu \mathrm{m}$. The number of intersections of the eYFP-positive fibers with the probe were added for every subregion of interest per animal to calculate the total number of intersections. The sampling design yielded an average of 380 fiber/probe intersections counted at an average of 85 sampling sites per subregion per animal. The grid $(x y)$ used for sampling was different between subregions, ranging from $175 \times 100$ to $290 \times 290 \mu \mathrm{m}$ for all animals.

To estimate the eYFP fiber length, we used a formula described previously by Mouton and colleagues (Calhoun and Mouton, 2001; Mouton et al., 2002): $\mathrm{L}=2 \times\left(\sum Q_{\mathrm{i}}\right) \times v / a \times 1 /$ ssf, where $Q_{\mathrm{i}}$ is the total number of intersections counted in a subregion in an animal, $v$ is volume (grid $x \times$ grid $y \times$ post-processing thickness), $a$ is surface area of the hemisphere, and ssf is section sampling fraction (either $1 / 8$ or $1 / 4$ ). FLD in the subregions was calculated by the ratio of the total fiber length (L) and the mean volume of the subregion. The volume of each subregion was determined using the Cavalieri estimator probe in the Stereo Investigator software (Gundersen and Jensen, 1987). The mean volume of the total $\mathrm{mPFC}$ was $2.6 \pm 0.3 \mathrm{~mm}^{3}$. Shrinkage in the $z$ direction was assumed to be equal between animals and regions because all tissue was treated in the same manner. All quantification was done by a single experimenter, and, to prevent bias, all sections were coded and analyzed in a random manner. The coefficient of error ranged from 0.2 to 0.17 in the subregions of the PFC (for details, see Table 2).

\section{eYFP-positive cell plotting}

Contours of sections and brain ventricles were delineated with Stereo Investigator software at low magnification ( $20 \times$ dry objective) using sections stained according to the series 1 immunostaining procedure, viewed through an N2.1 filter cube. Injection sites were located by switching to the I3 filter cube. The areas including all eYFP-positive cell bodies of interest were delineated at low magnification $(2.5 \times)$. eYFPpositive interneurons along injection tracks, e.g., in the striatum, were ignored. Any fluorescent body with a diameter exceeding $10 \mu \mathrm{m}$ was interpreted as a neuron. All cells within delineated areas were systematically plotted at high magnification $(20 \times)$ using the software's "meander scan" option. $x-y-z$ positions of all cells were recorded to generate $3 \mathrm{D}$ overviews of the injection sites.

\section{CLSM}

Structures of interest were imaged with a Leica TCS-SP2 AOBS confocal instrument equipped with N2.1 and I3 filter cubes for visual fluorescence inspection and with argon-krypton and helium-neon lasers to provide laser illumination at wavelengths 488 and $594 \mathrm{~nm}$, respectively. We configured two imaging channels: (1) a "green" channel (488 nm excitation; 500-540 nm emission bandpass filtering); and (2) a "red" channel (594 $\mathrm{nm}$ excitation; 605-630 $\mathrm{nm}$ emission bandpass filtering). Sections double immunostained with anti-NeuN and anti-GFP antibodies were inspected first visually using the N2.1 red filter cube to identify the mPFC subdivision to be scanned. Scanning of these sections for mapping pur- poses was conducted with a $20 \times$ dry objective lens, numerical aperture (NA) 0.7. For high-resolution scanning (eYFP-positive fibers in mPFC divisions and cortical layers), we applied a $63 \times$ glycerin immersion objective lens (NA 1.3) at $8 \times$ electronic zoom, Airy disk $=1$. The sections containing ChAT-immunostained neurons were scanned at low magnification (20X dry lens) in both channels to delineate the location of eYFP-expressing "infected" neurons relative to the non-eYFP expressing, "non-infected" ChAT-immunopositive population of basal forebrain neurons and to verify at the same time at higher magnification $(20 \times$ dry lens or $63 \times$ immersion lens) whether all eYFP-positive neurons indeed coexpressed ChAT.

All scanning performed was $z$-scanning, at $1024 \times 1024$ pixels, eightbit sampling, and in "sequential" mode. Images to be used for illustration purposes were $Z$-scanned with the $20 \times$ dry lens at $2.048 \times 2048$ pixels or with the $63 \times$ immersion lens at $1024 \times 1024$ pixels. After acquisition, the images of fibers and fiber terminals in mPFC acquired at the highest magnification were deconvoluted with Huygens Professional software (Scientific Volume Imaging). Z-series of confocal images were imported in NIH ImageJ (http://rsb.info.nih.gov.ij/). With this image processing software, we first applied background subtraction according to the "Rolling Ball" algorithm and then prepared Z-projection views. Final figure preparation, including adjustments of brightness and contrast, was done using Photoshop software (version 6.0; Adobe Software).

\section{Statistics}

Statistical analyses was performed with the SPSS package version 20.0 (IBM). Correlations were assessed using bivariate Spearman's rank correlation coefficients. Statistical significance level was set at $p<0.05$.

\section{Results}

To specifically label cholinergic neurons at different locations in the basal forebrain, nine ChAT-Cre mice were injected with a single injection of AAV containing a double-floxed eYFP gene (Sohal et al., 2009) at a specific location within the basal forebrain (Fig. 1A). Compact and discrete populations of eYFP-positive neurons were found at topographical positions in accordance with the stereotaxic virus injection coordinates (Figs. $1 B-E$, $2 A, B$; Table 1). Virus injections resulted in eYFP-positive neurons in the nucleus of the vertical band of Broca (VDB), nucleus of the horizontal band of Broca (HDB), ventral pallidum (VP), magnocellular preoptic nucleus (MCPO), substantia innominata (SI), and basal nucleus (Figs. 1, 2). To verify that eYFP-positive neurons were indeed cholinergic, we immunostained sections with ChAT antibody (Fig. 2C-F). All cell bodies of eYFP-positive neurons showed colocalization with ChAT immunofluorescence. Neurons positive for both eYFP and ChAT appeared embedded in larger populations of ChAT-positive neurons (Fig. $2 A-C)$. At some injections, we observed scattered eYFP-positive cells along the needle track, for instance, in the caudate-putamen complex (Fig. 2C), nucleus accumbens, VP, and bed nucleus of the stria terminalis (BNST). The morphology of these neurons was similar to that reported for local cholinergic striatal interneurons (Armstrong et al., 1983; Bolam et al., 1984; Phelps et al., 1985; Butcher and Woolf, 2004). In sections immunostained with anti-ChAT antibodies, these scattered eYFP-positive neurons were also immunopositive for ChAT. We found differences in the number of transfected cells between the different injection sites, reflecting differences in the density of cholinergic neurons throughout the basal forebrain (Zaborszky et al., 1999). In all nine cases of ChAT-Cre mice, the density of the transfected, eYFP-expressing neurons matched the distribution patterns of cholinergic neurons in the ChAT-GFP control mice: aggregated in VDB and HDB and more loosely distributed in VI, SI, and nucleus basalis (NB; Fig. 2G-I; Zaborszky et al., 1999). Because of the differences in the total number of transfected neurons, we 


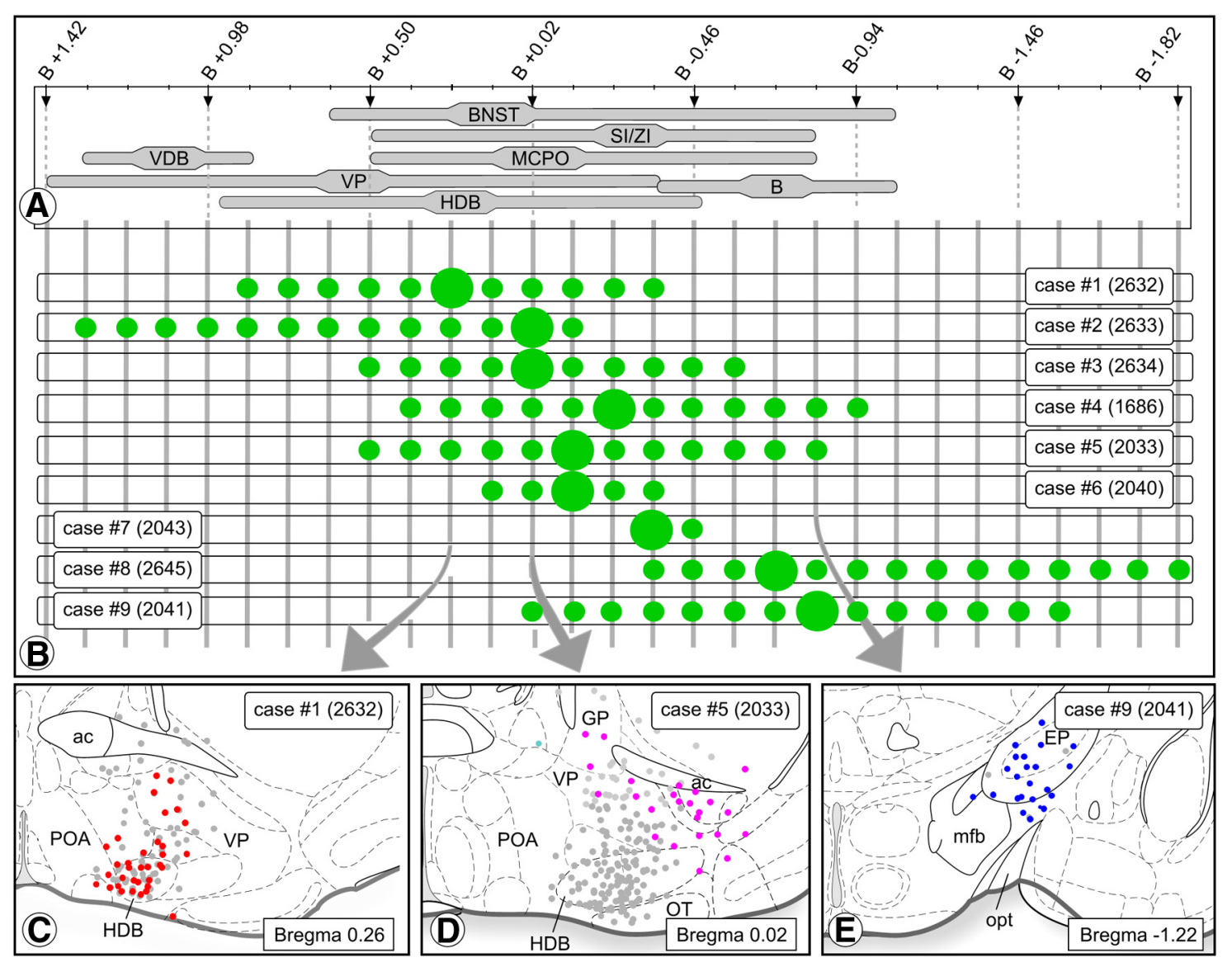

Figure 1. Injections along the axis of the basal forebrain result in labeling of discrete groups of cholinergic neurons along the basal forebrain. $A$, Positions of the basal forebrain nuclei with respect to bregma. $\boldsymbol{B}$, Graphical representation of the coronal levels in which transfected neurons occurred for the nine injection sites. Small green dots indicate levels at which transfected neurons were visible. The big green dots indicate the level with most transfected neurons per animal. $\mathbf{C}-\boldsymbol{E}$, Examples of three cases at three different coronal levels. Transfected cells for that animal are indicated in color. Transfected ChAT neurons in all other animals are indicated in gray. ac, Anterior commissure; B, bregma; EP, entopeduncular nucleus; GP, globus pallidus; mfb, medial forebrain bundle; opt, optic tract; $0 \mathrm{~T}$, olfactory tubercle; POA, preoptic area; Zl, zona incerta.

decided to analyze relative rather than absolute fiber length hereafter.

\section{Location-dependent cholinergic innervation of mPFC via either layer I or white matter}

In the rat brain, it was found that cholinergic fibers leaving the basal forebrain take a number of trajectories (Eckenstein et al., 1988). Here, we tested whether similar projection patterns exist in the mouse brain and whether the trajectories to the target regions depend on the location of eYFP-positive neurons in the basal forebrain. To identify fiber trajectories of eYFP-positive fibers, we compared fiber density in several areas surrounding the basal forebrain (Table 1; scoring from - for no fibers to +++ for high density of fibers). As in the rat, we found different pathways of cholinergic fibers leaving the basal forebrain (Fig. $3 A-F$ ). The pathways taken depended strongly on the location of the injection. Based on the fluorescence and fiber quantifications, we identified four trajectories along which eYFP-positive fibers traveled from the parent cell bodies to their cortical targets (Fig. 3A; Table 1). The first route, which we designated the "medial route" (Fig. 3A, labeled 1), was found in the mice that received the most rostral injections (mice 1-3) and that had eYFP-positive cell bodies located in the vertical and horizontal limbs of the diagonal band. Their fibers traveled parallel to the pial surface in the anteromedial direction and, anterior to the genu of the corpus callosum, turned in the dorsal direction. They entered the medial orbital cortex in which they continued their course in layer I toward their destinations in the IL and PL subdivisions of mPFC (Fig. 3B). Profuse branching occurred in layer I of IL and PL, with dense, hypervaricose ramifications (Fig. 3E).

The second route (the "septal route"; Fig. 3A, labeled 2) was found also in mice that received the most frontal injections (mice $1-3$; Table 1). It originated from loci with eYFP-positive cell bodies in the horizontal limb of the diagonal band dorsally, from which fibers traveled into the medial septum. The contingent of eYFP-positive fibers taking this septal route split into a portion of fibers that entered the fornix and continued to run in this tract along its dorsocaudally directed curve to innervate the hippocampus. The eYFP-positive septal route fibers that did not join the fornix continued their course in the dorsal direction until they hit the lower edge of the corpus callosum. They subsequently perforated the corpus callosum (Fig. $3 \mathrm{C}$ ) and traveled farther in the dorsal direction in the deep layers of the $\mathrm{ACv}$ and, more dorsally, in the ACd. Both in ACv and ACd branches of these deep "supply fibers" took a radial direction to enter more superficial cortical layers and branched profusely into varicose end ramifications (examples of ramification patterns in Fig. 3E).

The third route was predominantly found in mice that received injections in the caudal portions of the basal forebrain (mice 4-9; Table 1). Fibers originated from eYFP-positive cell bodies lying in the caudal portion of the horizontal limb of the diagonal band. These fibers took a dorsolaterally oriented direc- 

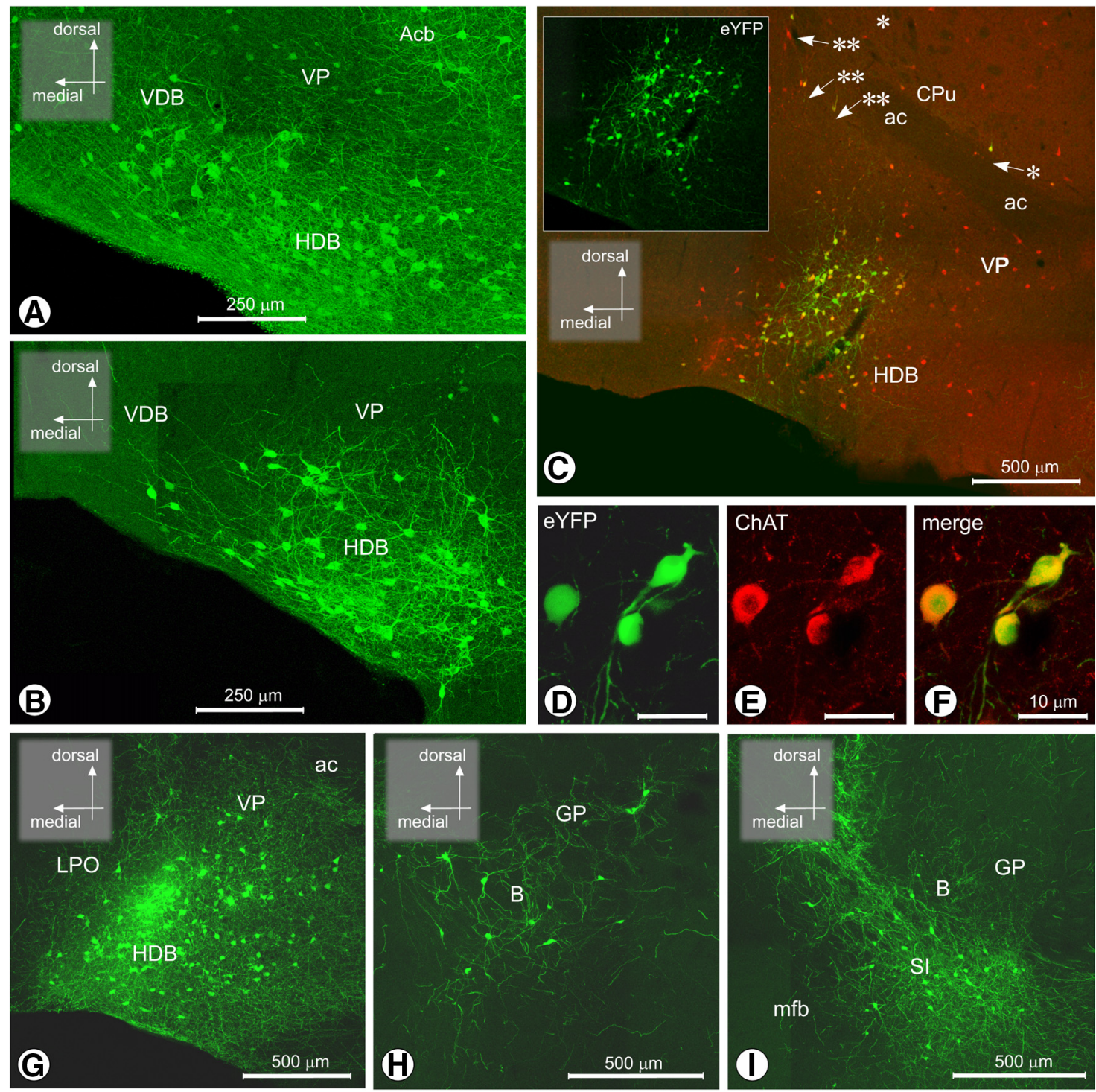

Figure 2. Transfection of ChAT neurons in the basal forebrain. A, ChAT neurons in a ChAT-GFP mouse are present in multiple nuclei of the basal forebrain and interspersed with non-ChAT neurons. $\boldsymbol{B}$, Injection of Cre-dependent virus in a ChAT-Cre mouse (mouse 1) results in eYFP expression in cholinergic neurons around the injection site. Images of $\boldsymbol{A}$ and $\boldsymbol{B}$ are made in the same brain area for comparison. C, ChAT-immunostained section. Composite low-power CLSM image showing eYFP-positive neurons in the injection site (green; mouse 2) in the context of the distribution of ChAT neurons (red). Note eYFP-positive neurons in the caudate-putamen complex (asterisk) and along the injection track (double asterisks). These are interneurons. Inset shows the Z-projected image acquired in the $488 \mathrm{~nm}$ green eYFP channel. $\boldsymbol{D}-\boldsymbol{F}$, Images acquired in different channels in the CLSM in eYFP-ChAT immunofluorescence sections (mouse 2). $\boldsymbol{D}$, eYFP-positive neurons in the green channel. $\boldsymbol{E}$, ChAT-positive cells in the red channel. $\boldsymbol{F}$, Merge image. Scale bar, $10 \mu \mathrm{m}$. Images were acquired in sequential mode. All eYFP-positive cells that we studied also expressed ChAT immunofluorescence. G, Transfected neurons (green) in mouse 4. $\boldsymbol{H}$, Transfected neurons in mouse 8. I, Transfected neurons in mouse 9. Abbreviations as in Figure 1. Acb, Nucleus accumbens; (Pu, caudate-putamen; LPO, lateral preoptic area.

Table 1. Injection sites (sites containing eYFP-positive cell bodies) and fiber trajectories per animal

\begin{tabular}{|c|c|c|c|c|c|c|c|c|c|}
\hline Case & Injection spot & $\begin{array}{l}\text { Distance }(\mathrm{mm}) \\
\text { behind bregma }\end{array}$ & $\begin{array}{l}\text { Medial route } \\
\text { (route 1) }\end{array}$ & $\begin{array}{l}\text { Septal route } \\
\text { (route 2) }\end{array}$ & $\begin{array}{l}\text { Internal capsule } \\
\text { route (route 3) }\end{array}$ & $\begin{array}{l}\text { Lateral route } \\
\text { (route 4) }\end{array}$ & $\begin{array}{l}\text { eYFP-positive fibers in the } \\
\text { anterior commissure }\end{array}$ & $\begin{array}{l}\text { eYFP-positive fibers in } \\
\text { the fornix }\end{array}$ & $\begin{array}{l}\text { eYFP-positive fibers in the } \\
\text { stria terminalis }\end{array}$ \\
\hline 1 & Anterior HDB & -0.26 & ++ & ++ & - & - & - & + & + \\
\hline 2 & $\begin{array}{l}\text { Anterior HDB } \\
\text { Mid/posterior }\end{array}$ & 0.02 & ++ & + & - & - & - & + & + \\
\hline 3 & $\begin{array}{l}\text { HDB } \\
\text { Mid HDB/VP/ }\end{array}$ & 0.02 & ++ & + & - & + & + & + & + \\
\hline 4 & MCPO & 0.22 & + & + & + & + & - & ++ & ++ \\
\hline 5 & VP/NB & 0.1 & + & + & + & + & - & - & ++ \\
\hline 6 & BNST/NB & 0.1 & - & - & ++ & + & - & - & +++ \\
\hline 7 & NB & 0.34 & - & - & + & ++ & + & - & + \\
\hline 8 & $\mathrm{SI} / \mathrm{ZI}$ & 0.7 & - & - & + & ++ & - & - & + \\
\hline 9 & NB & 0.82 & - & - & +++ & ++ & + & - & ++ \\
\hline
\end{tabular}

We identified four main routes taken by YFP-positive fibers from their parent cell bodies to mPFC targets: medial, septal, internal capsule, and lateral. Zl, Zona incerta. 

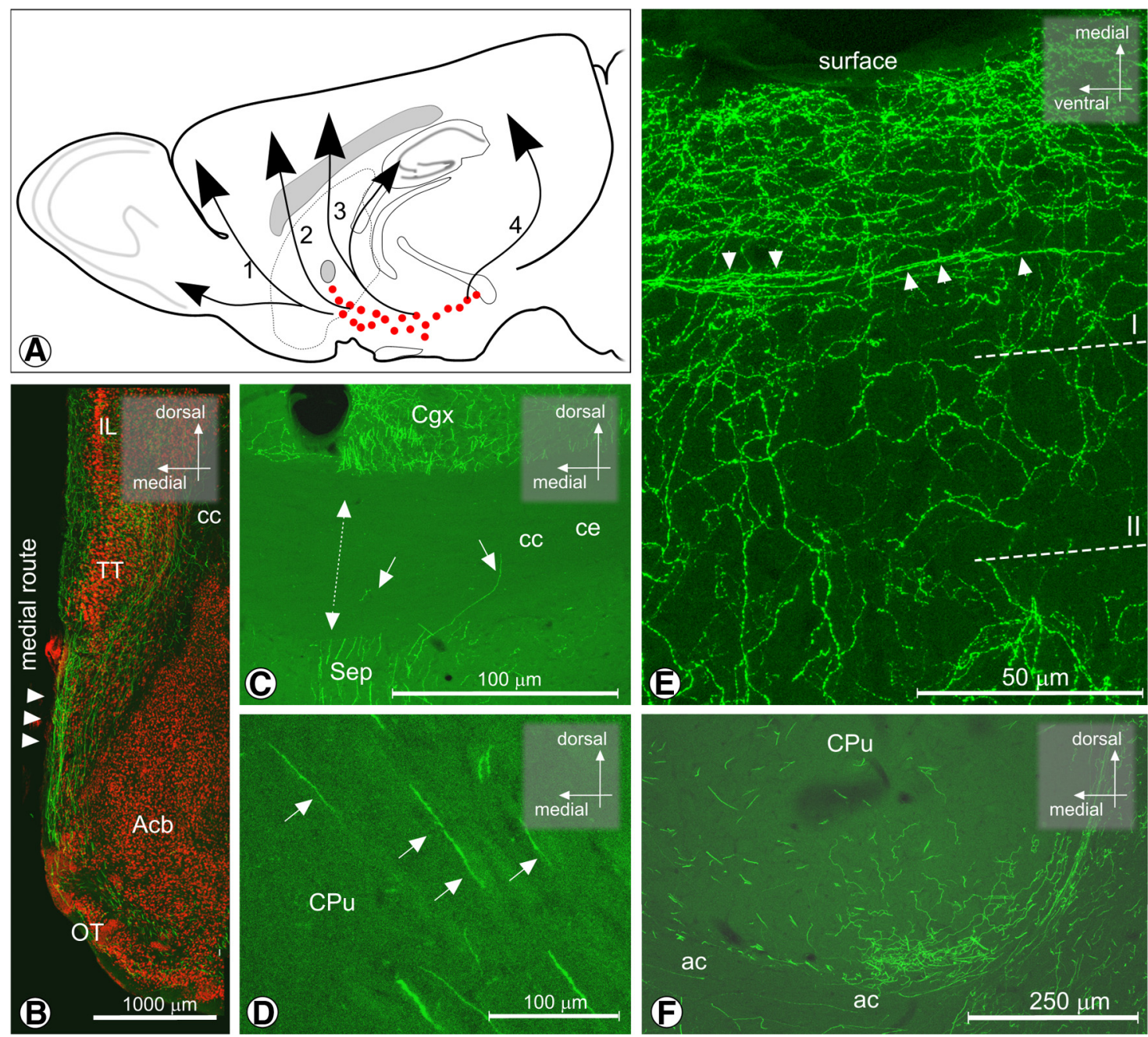

Figure 3. Cholinergic fibers originating in the basal forebrain take four different routes to the cortex. $\boldsymbol{A}$, Scheme summarizing the location of eYFP-positive cholinergic neurons and the routes taken by eYFP-positive fibers to their targets. A continuous system of fibers fans out from the cholinergic cell bodies to their cortical target areas, taking various routes. 1, Medial route of fibers parallel to the brain surface from the VDB, via taenia tecta (TT), and rostral to the forceps minor of the corpus callosum (cc) into layer I of mPFC. 2, Septal route, with fibers perforating the corpus callosum. 3, Fibers embedded in the capsula interna. 4, Fibers traveling initially laterally and then turning dorsally, i.e., bending around the distal end of the internal capsule to enter temporal and parietal cortices. Fibers with destination olfactory bulb take route 1 , whereas fibers entering the fornix on their way to the hippocampus follow route 2. B, eYFP-positive fibers following the medial route (arrowheads). C, Septal route: corpus callosum penetrating eYFP-positive fibers (arrows). D, Route 3: eYFP-positive fibers in dorsomedially directed capsula externa fiber bundles in the CPu (arrows; section at level of the anterior commissure crossing). $\boldsymbol{E}$, Route 4 , fibers traveling laterally ventral to the forceps major of the corpus callosum and then proceeding dorsally in the capsula externa. cc, corpus callosum; ce, capsula externa; $0 \mathrm{~T}$, olfactory tubercle; Sep, septum. $\boldsymbol{F}$, Terminal distribution of eYFP-positive fibers in the outer layers of ACv at high magnification. Arrowheads indicate fibers arriving via route 1 .

tion (Fig. $3 A, D$, labeled 3). Some eYFP-positive fibers joined the stria terminalis and on guidance of this tract innervated hypothalamic targets, whereas the remaining fibers entered the bundles of the anterior portion of the capsula interna and could be followed all the way to the deep layers of ACd and Fr2 of mPFC. Here, the fibers mixed with fibers arriving via the septal route, and they innervated all layers of these cortical regions.

Finally, in mice that received injections in the caudal parts of the basal forebrain (mice 7-9; Table 1), we found that fibers emanating from eYFP-positive cell bodies located in the VP, the caudal portion of the horizontal limb of the diagonal band, and NB distributed along a fourth route (Fig. 3 A, F, labeled 4). These eYFP-positive fibers ran from their parent cell bodies in the lateral direction, took a tight turn around the ventral end of the external capsule, and continued in a dorsal direction, as fibers embedded superficially in the external capsule. The eYFPpositive fibers traveled farther dorsally, bent in the radial direction, and participated in the innervation of parietal sensory and motor cortices. A few fibers reached as far dorsally as Fr2, in which they mixed with fibers arriving via the second and third routes.

Hence, injections in rostral areas of the basal forebrain resulted in eYFP-positive fibers leaving the basal forebrain through medial pathways 1 and 2 (Fig. 3; Table 1). In contrast, injections in caudal parts of the basal forebrain resulted in eYFP-positive fibers that traveled in a more lateral direction through pathways 3 and 4 but not pathways 1 and 2 (Fig. 3; Table 1). Only the first, medial route innervated the cortex via layer I. The other three pathways all entered the cortex via the white matter underlying layer VI. Thus, the spatial organization of cholinergic innervation of the mPFC depends on the location of the cholinergic neurons within the basal forebrain and the fiber tract that is taken by their axons. All axonal projections were strictly ipsilateral.

Two categories of eYFP-positive fibers were observed. The first category included thin nontapering fibers with a hypervaricose morphology, i.e., high-frequency sequences of equidistant, 


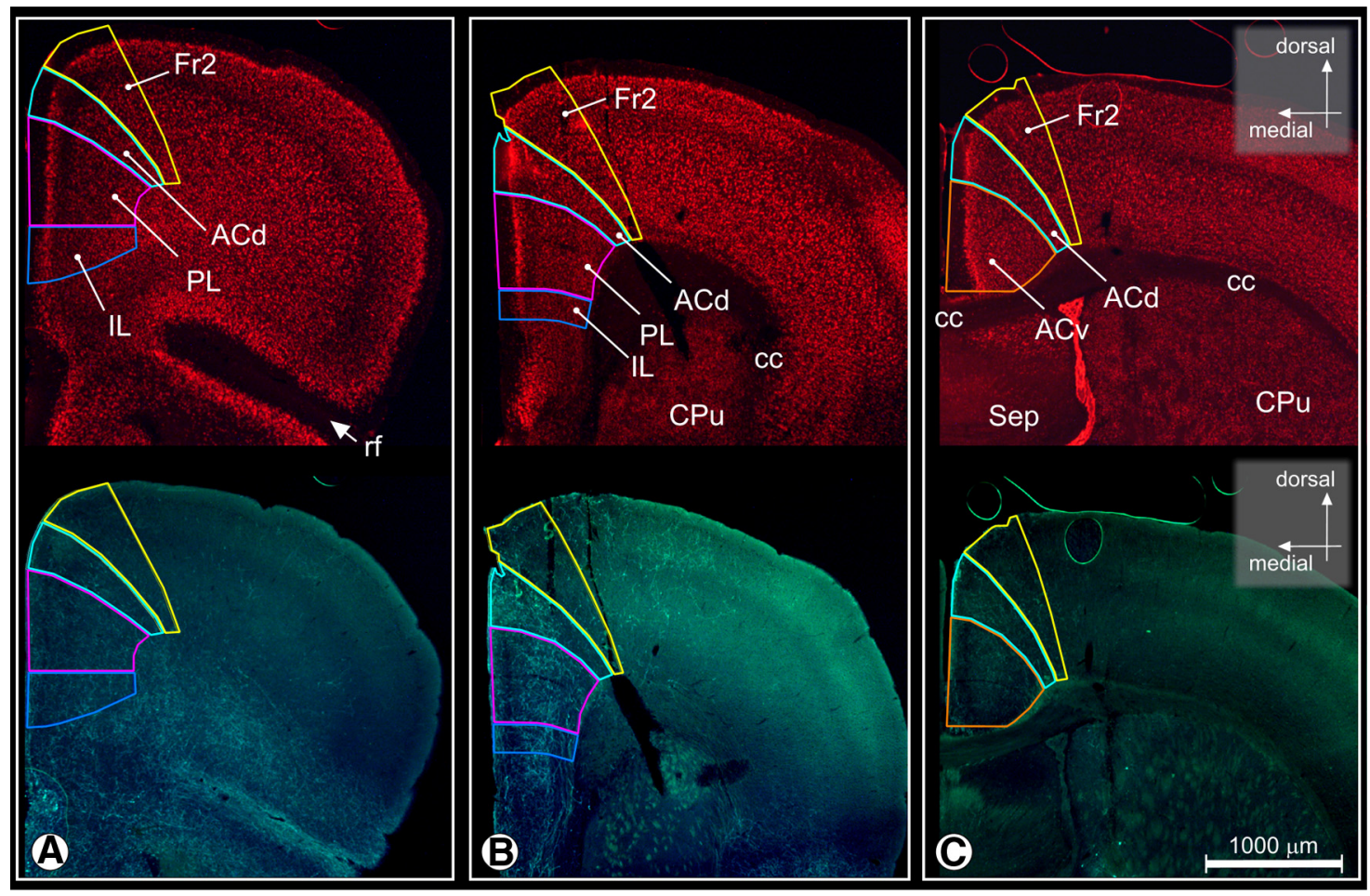

Figure 4. Overview of $\mathrm{mPFC}$ parcellation in Stereo Investigator at low magnification $(2.5 \times)$ : coronal sections at three levels: anterior $(\boldsymbol{A})$, intermediate $(\boldsymbol{B})$, and posterior $(\boldsymbol{C})$ based on the description of Van De Werd et al. (2010): Fr2 (yellow), ACd (light blue), PL (purple), IL (dark blue), and ACv (orange). Top row, NeuN reference stain; bottom row, eYFP-positive fibers in the same slices. If, Rhinal fissure.

en passant boutons, and that have a tendency of branching perpendicularly. These fibers were arranged in a diffuse network-like distribution pattern (Fig. 3E). Fibers of this type were seen in all densely innervated cortical layers. The en passant way of formation of varicosities was very omnipresent. Terminal rosettes were absent; that is, we did not observe sideways "sprouting" of very short fiber collaterals ending in a handful of terminal varicosities. The second category of fibers consisted of thicker, less varicose, more linear eYFP-positive fibers oriented in PL, IL, and ACv parallel to the pial surface (Fig. 3E, triangles), branching off collaterals often in a perpendicular way ("T-branching") and contributing to the diffuse varicose cortical innervation. In IL, fibers of this type formed the continuation of fibers arriving via the medial route and may be considered as supply fibers. In ACd and $\mathrm{Fr} 2$, the more oblique/radial orientation of fibers of this type suggests that they form the intracortical continuation of eYFP fibers arriving via routes 2 and 3 . Thus, in PL and IL, fibers arrive via routes 1 and 2 , whereas their collaterals subsequently mix.

\section{Distinct projection patterns from different locations in the basal forebrain}

Because different groups of cholinergic neurons along the frontocaudal axis of the basal forebrain target the cortex through different pathways, we next asked the question whether different cholinergic populations in the basal forebrain innervate different regions of the mPFC (Fig. 4). All mPFC subdivisions contained eYFP-positive fibers but to a different degree depending on injection location (Fig. 5). To test the hypothesis that a topographical mapping exists between basal forebrain cholinergic cells and their prefrontal projections, we quantified the amount of fibers in the mPFC and compared different mPFC subregions (Table 2). Although in the rat the total length of cortical and MPFC cholinergic fibers has been estimated (Mechawar et al., 2000), little is known regarding cholinergic fiber length in mice. Previously, total cholinergic fiber length in the neocortex of mice was estimated to be $\sim 600 \mathrm{~m}$ using AChE immunohistochemistry and stereological analysis (Boncristiano et al., 2002). We stereologically determined the total cholinergic fiber length and FLD in the mouse $\mathrm{mPFC}$ and its subregions. On average, we found a cholinergic FLD of $3.7 \mathrm{~m} / \mathrm{mm}^{3}$ across all the injection sites and regions in the $\mathrm{mPFC}$. Because in rat PFC a length density of $13 \mathrm{~m} / \mathrm{mm}^{3}$ was reported (Mechawar et al., 2000), this suggests that the cholinergic FLD is on the same order of magnitude in mice and rats. However, it is impossible to compare directly because we used virus injections in restricted parts of the basal forebrain, whereas they used an immunostaining approach. After this, we calculated the eYFP-positive FLD in each MPFC subregion (Table 2). For several mPFC areas, we found a striking dependence of FLD on location of injection along the frontocaudal axis. This was most pronounced for Fr2 and for the ACd and IL cortex (Fig. 5A).

The relative FLD in Fr2 steadily increased from $<4 \%$ of the total FLD in the mPFC of mice that received virus injections at rostral sites (e.g., mouse 1; Fig. 5A) to between 35 and $42 \%$ for mice that received injections at caudal sites in the basal forebrain (mice 7-9). There was a significant correlation between the injection location along the baseline and the relative FLD values $(r=$ $0.92, p<0.001)$. This increase in relative FLD in the Fr2 coincides with the increasingly larger portion of the injection site within the NB. This suggests that the caudal part of this cholinergic nucleus could be the main source of the ascending cholinergic fibers to the Fr2 region.

Similarly to Fr2, the FLD in the ACd region increased with more caudal injections (Fig. 5A). The relative density of the fibers steadily increased in par with the location of the injection site along the rostrocaudal baseline $(r=0.87, p<0.005)$. The FLD is 

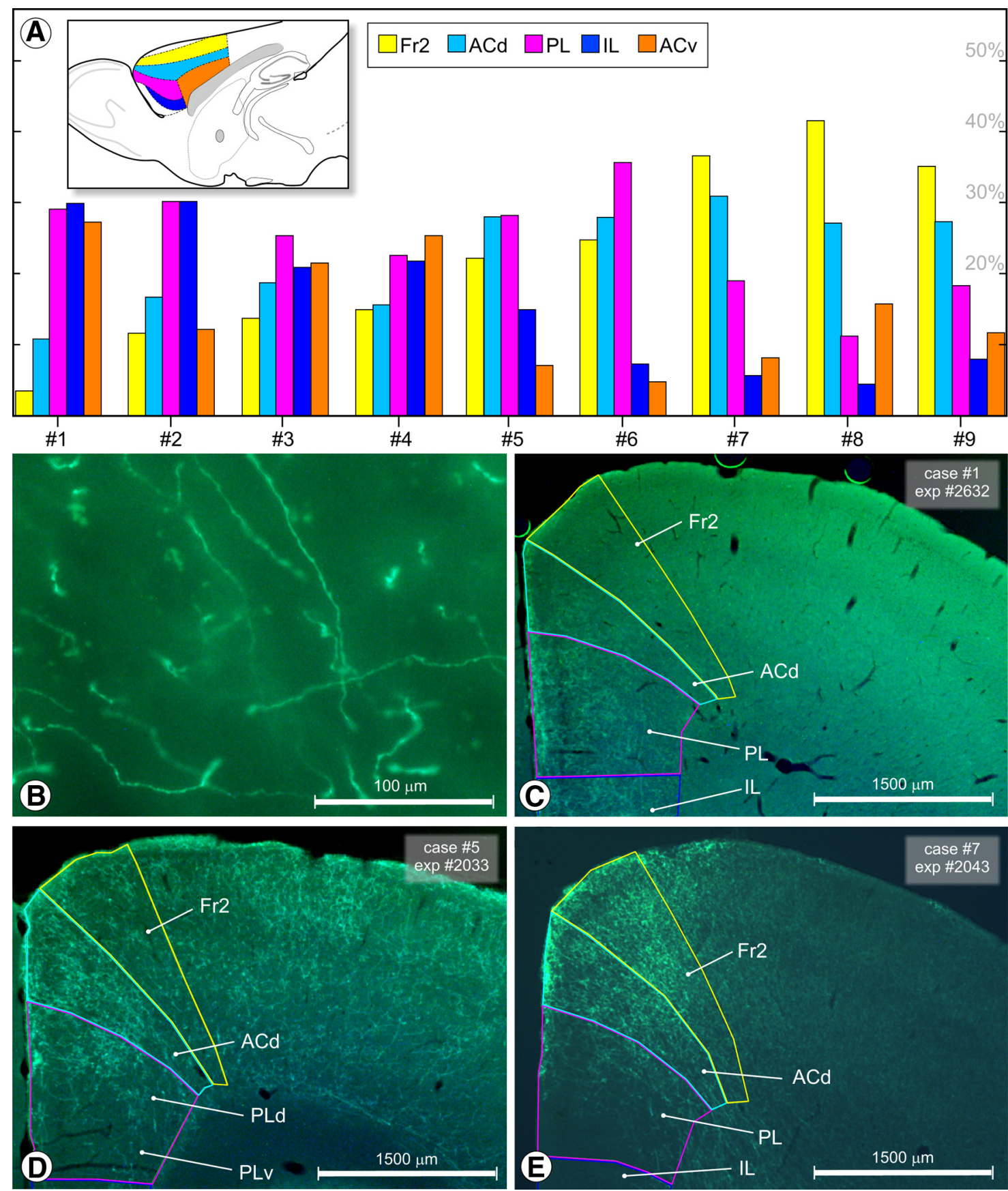

Figure 5. $A$, Graphical representation of FLD in the subregions of $\mathrm{mPFC}$ for the nine injection sites, from anterior (case \#1) to posterior-lateroposterior (case \#9). Bars represent percentages of total FLD for each case. $\boldsymbol{B}$, High-power view (100× objective) of fiber distribution in $\mathrm{mPFC}$. C $-\boldsymbol{E}$, Various distributions of eYFP-positive fibers in different cases showing shift of highest density from ventral to dorsal associated with anteroposterior positioning of injection site. C, Anterior injection (case\#1) with high fiber density in PL and IL. D, Intermediate injection (case \#5) with high density in the PLd and low density in the PLv and IL. E, More posterior injection (case \#7) with high density in Fr2 and ACd and low density in PL and IL.

relatively low in rostrally injected mice $1-4(10-19 \%)$ and relatively high (up to $31 \%$ in mice $7-9$ ) in mice with the injection spots visible most caudally/laterally.

In contrast to the FLD pattern observed for the Fr2 and ACd with a stronger innervation from the caudal regions of the basal forebrain, the PL and IL areas of the MPFC showed an opposite dependence on injection location (Fig. 5). In PL, for the mice with a rostrally positioned injection site (mice 1 and 2), the FLD was high (28-30\%) and decreased with more caudally positioned injections ( $11-19$ in mice $6-9 ; r=-0.71, p<0.05$; Fig. $5 A$ ). As in PL, FLD values in IL showed a clear correlation with the ros- trocaudal position of the injection sites in $(r=-0.91, p<0.001$; Fig. 5A). The relative eYFP-positive fiber density in mice 1 and 2 was high (FLD of 29-30\%), and the FLD decreased to its lowest values in the caudalmost injections (mice 7-9, 4-8\%; Fig. 5A). In the ACv, the FLD followed a similar trend as the IL and PL, but there was no significant correlation with injection site along the frontocaudal axis $(r=-0.54, p=$ NS; Fig. $5 A)$.

Thus, Fr2 and ACd show an opposite pattern of cholinergic innervation compared with IL and PL (Fig. 5A). In rostral injection loci (e.g., $\mathrm{HDB}, \mathrm{VDB}$, and/or MCPO), the highest FLD was measured in the more ventrally located subdivisions of mPFC 
Table 2. Stereological estimation of FLD and relative fiber density in the $\mathrm{mPFC}$

\begin{tabular}{|c|c|c|c|c|c|}
\hline Region & $\begin{array}{l}\text { Volume } \\
\left(\mathrm{m}^{3}\right)\end{array}$ & $\begin{array}{l}\text { Estimated fiber } \\
\text { length }(\mathrm{m})\end{array}$ & $\begin{array}{l}\text { Estimated FLD } \\
\left(\mathrm{m} / \mathrm{m}^{3}\right)\end{array}$ & $\begin{array}{l}\text { Coefficient error } \\
\text { (Gundersen and } \\
\text { Jensen, 1987) }\end{array}$ & Relative FLD \\
\hline \multicolumn{6}{|l|}{ Case \#1 } \\
\hline $\mathrm{Fr} 2$ & 0.618 & 0.331 & 0.535 & 0.12 & $3.55 \%$ \\
\hline $\mathrm{ACd}$ & 0.541 & 0.885 & 1.635 & 0.08 & $10.83 \%$ \\
\hline $\mathrm{ACv}$ & 0.411 & 1.683 & 4.099 & 0.06 & $27.15 \%$ \\
\hline PL & 0.540 & 2.352 & 4.357 & 0.05 & $28.86 \%$ \\
\hline IL & 0.134 & 0.597 & 4.470 & 0.06 & $29.61 \%$ \\
\hline \multicolumn{6}{|l|}{ Case \#2 } \\
\hline $\mathrm{Fr} 2$ & 0.886 & 0.898 & 1.014 & 0.09 & $11.62 \%$ \\
\hline $\mathrm{ACd}$ & 0.789 & 1.145 & 1.454 & 0.09 & $16.66 \%$ \\
\hline $\mathrm{ACv}$ & 0.563 & 0.593 & 1.055 & 0.10 & $12.08 \%$ \\
\hline $\mathrm{PL}$ & 0.699 & 1.815 & 2.599 & 0.06 & $29.77 \%$ \\
\hline$\| \mathrm{L}$ & 0.119 & 0.310 & 2.608 & 0.08 & $29.88 \%$ \\
\hline \multicolumn{6}{|l|}{ Case \#3 } \\
\hline $\mathrm{Fr} 2$ & 0.705 & 2.107 & 2.990 & 0.06 & $13.76 \%$ \\
\hline $\mathrm{ACd}$ & 0.697 & 2.8827 & 4.055 & 0.05 & $18.67 \%$ \\
\hline $\mathrm{ACv}$ & 0.378 & 1.759 & 4.654 & 0.05 & $21.42 \%$ \\
\hline $\mathrm{PL}$ & 0.494 & 2.709 & 5.482 & 0.04 & $25.23 \%$ \\
\hline IL & 0.138 & 0.628 & 4.543 & 0.04 & $20.91 \%$ \\
\hline \multicolumn{6}{|l|}{ Case \#4 } \\
\hline $\mathrm{Fr} 2$ & 0.512 & 2.259 & 4.412 & 0.07 & $14.86 \%$ \\
\hline $\mathrm{ACd}$ & 0.444 & 2.067 & 4.657 & 0.07 & $15.69 \%$ \\
\hline $\mathrm{ACv}$ & 0.343 & 2.572 & 7.508 & 0.05 & $25.29 \%$ \\
\hline PL & 0.148 & 0.982 & 6.657 & 0.06 & $22.43 \%$ \\
\hline IL & 0.332 & 2.144 & 6.449 & 0.06 & $21.73 \%$ \\
\hline \multicolumn{6}{|l|}{ Case \#5 } \\
\hline $\mathrm{Fr} 2$ & 1.129 & 4.360 & 3.860 & 0.05 & $24.62 \%$ \\
\hline $\mathrm{ACd}$ & 0.930 & 4.540 & 4.884 & 0.04 & $27.83 \%$ \\
\hline $\mathrm{ACv}$ & 0.553 & 0.674 & 1.219 & 0.10 & $4.75 \%$ \\
\hline PL & 0.819 & 4.010 & 4.898 & 0.05 & $35.35 \%$ \\
\hline IL & 0.186 & 0.491 & 2.640 & 0.06 & $7.44 \%$ \\
\hline \multicolumn{6}{|l|}{ Case \#6 } \\
\hline $\mathrm{Fr} 2$ & 1.057 & 4.732 & 4.479 & 0.02 & $39.97 \%$ \\
\hline $\mathrm{ACd}$ & 1.067 & 5.404 & 5.063 & 0.02 & $27.19 \%$ \\
\hline $\mathrm{ACv}$ & 1.096 & 0.947 & 0.863 & 0.04 & $11.63 \%$ \\
\hline PL & 0.169 & 1.089 & 6.431 & 0.04 & $18.19 \%$ \\
\hline IL & 0.075 & 0.101 & 1.354 & 0.08 & $8.03 \%$ \\
\hline \multicolumn{6}{|l|}{ Case \#7 } \\
\hline $\mathrm{Fr} 2$ & 0.625 & 5.753 & 9.206 & 0.04 & $36.44 \%$ \\
\hline $\mathrm{ACd}$ & 0.609 & 4.728 & 7.764 & 0.05 & $30.74 \%$ \\
\hline $\mathrm{ACv}$ & 0.416 & 0.855 & 2.056 & 0.10 & $8.14 \%$ \\
\hline PL & 0.506 & 2.431 & 4.802 & 0.06 & $19.01 \%$ \\
\hline IL & 0.127 & 0.183 & 1.432 & 0.10 & $5.67 \%$ \\
\hline \multicolumn{6}{|l|}{ Case \#8 } \\
\hline Fr2 & 0.824 & 1.446 & 1.755 & 0.07 & $41.25 \%$ \\
\hline $\mathrm{ACd}$ & 0.692 & 0.796 & 1.151 & 0.09 & $27.05 \%$ \\
\hline $\mathrm{ACv}$ & 0.465 & 0.314 & 0.674 & 0.16 & $15.84 \%$ \\
\hline PL & 0.484 & 0.232 & 0.480 & 0.17 & $11.27 \%$ \\
\hline IL & 0.155 & 0.030 & 0.195 & 0.15 & $4.58 \%$ \\
\hline \multicolumn{6}{|l|}{ Case \#9 } \\
\hline Fr2 & 0.647 & 5.670 & 8.767 & 0.04 & $34.97 \%$ \\
\hline $\mathrm{ACd}$ & 0.607 & 4.135 & 6.816 & 0.05 & $27.19 \%$ \\
\hline $\mathrm{ACv}$ & 0.509 & 1.485 & 2.917 & 0.07 & $11.63 \%$ \\
\hline PL & 0.365 & 1.663 & 4.559 & 0.05 & $18.19 \%$ \\
\hline IL & 0.119 & 0.239 & 2.012 & 0.09 & $8.03 \%$ \\
\hline
\end{tabular}

Cases are arranged 1-9 according to the rostral to caudolateral position of their injection spots. A graphical representation of the FLD is provided in Figure $5 A$.

such as IL and PL always relative to the more dorsal areas. Mice with injections positioned more caudally (e.g., SI and NB) had their highest FLD in the more dorsally located mPFC subdivisions (e.g., ACd and Fr2) relative to the more ventral mPFC subdivisions. Close visual inspection of sections revealed a secondary, intradivisional distribution pattern of eYFP-positive fi- bers in the PL (Fig. 5D). eYFP-positive fiber distribution in this region was not uniform. A sharp decrease in fiber density occurred between the dorsal portion of PL (PLd) and its ventral portion (PLv). This difference in fiber distribution between PLd and PLv was noticeable in mice 5-9. The stereological probe that we used was too big compared with PL subregion diameter to obtain statistically accurate measurements to test differences in FLD between these subdivisions.

To complete the picture of cholinergic PFC innervation, it should be noted that other divisions of the PFC, i.e., orbitofrontal cortex, and the adjacent agranular insular cortex also receive substantial cholinergic innervation. In all cases, we observed dense eYFP-positive fiber labeling in agranular insular cortex. In the medial, ventral, and lateral orbitofrontal cortices, we found scattered eYFP expression in all cases, with a focus of dense eYFPpositive labeling in case 4 .

\section{Laminar specificity of innervation by rostral and caudal cholinergic neurons}

Given our findings that different locations in the basal forebrain differentially innervate different $\mathrm{mPFC}$ regions and that they reach their targets through different pathways, we asked whether the different cholinergic populations in the basal forebrain exhibit layer specificity in their projections. We estimated the fiber density in a semiquantitative manner (scoring + for low amounts of fibers and ++++ for high amounts of fibers; Table 3 ). In general, the highest fiber density appeared in all mice in the deepest layers (layers V and VI). Within the superficial cortical layers, the highest fiber density was usually observed in layer I, followed by layer III. A consistent observation was the relatively low presence of fibers in layer II (Fig. 3E). This lower density in layer II was profoundly visible in animals with dense superficial eYFPpositive fiber distribution but also to some degree in $\mathrm{mPFC}$ subdivisions in animals with relatively less eYFP-positive fibers occurring in the superficial cortical layers.

Interestingly, in superficial layers I-III, a striking difference was found between the different injection sites, especially in PL, IL, and ACv (Fig. 6). First, in animals with rostral injection sites, there was an abundance of fibers in superficial layers, in addition to the deep layers (Fig. 6A). In stark contrast, the mice with caudal injection sites (mice 5-9) had a low fiber density in the superficial layers compared with deep layers (Fig. 6B; Table 3). Hence, caudally located cholinergic neurons innervate the deep layers of $\mathrm{PL}$, IL, and ACv strongly, whereas they hardly innervate the superficial layers. However, the rostrally located cholinergic neurons target both the superficial and deep layers. This suggests that the PL, IL, and ACv receive cholinergic inputs from two separate populations of basal forebrain neurons, one innervating all layers and one selectively innervating deep layers.

\section{Discussion}

In this study, we tested the hypothesis that there is a topographical mapping between cholinergic neurons in the basal forebrain and their targets in the mPFC. Using focal virus injections inducing Cre-dependent eYFP expression in ChAT-Cre mice, we demonstrate the following. (1) There are four cholinergic pathways from the basal forebrain to the mPFC. (2) These pathways originate in different parts of the basal forebrain and enter the mPFC via different layers. (3) There is a topographic organization between the cell bodies in the basal forebrain and their targets in the mPFC. The stereological data reveal a ventral to dorsal distribution pattern of cholinergic fibers in the mPFC on par with a rostral to caudal baseline location of the cell bodies in the basal 
Table 3. Qualitative rating of the cholinergic fibers across cortical layers in $\mathrm{mPFC}$ subdivisions

\begin{tabular}{|c|c|c|c|c|c|c|c|c|c|}
\hline Layer & Case \#1 & Case \#2 & Case \#3 & Case \#4 & Case \#5 & Case \#6 & Case \#7 & Case \#8 & Case \#9 \\
\hline \multicolumn{10}{|l|}{$\mathrm{Fr} 2$} \\
\hline I & ++ & ++++ & ++++ & +++ & +++ & ++ & ++ & +++ & +++ \\
\hline$\|$ & + & ++ & ++ & ++ & +++ & + & ++ & + & + \\
\hline III & ++ & ++ & ++++ & ++ & +++ & ++ & ++++ & ++ & ++ \\
\hline V & ++ & ++++ & ++ & ++ & ++++ & ++++ & ++++ & ++++ & +++ \\
\hline VI & + & ++++ & ++++ & +++ & ++++ & ++++ & ++++ & ++++ & ++++ \\
\hline \multicolumn{10}{|l|}{$\mathrm{ACd}$} \\
\hline I & +++ & ++++ & +++ & +++ & +++ & ++ & ++++ & +++ & ++ \\
\hline$\|$ & + & ++ & ++ & ++ & ++ & + & ++ & + & ++ \\
\hline III & ++ & ++ & +++ & +++ & +++ & ++ & +++ & + & +++ \\
\hline V & ++ & ++++ & ++ & ++++ & ++++ & ++++ & ++++ & +++ & ++++ \\
\hline VI & ++ & ++++ & ++++ & ++ & ++++ & ++++ & ++++ & ++++ & ++++ \\
\hline \multicolumn{10}{|l|}{$\mathrm{ACv}$} \\
\hline I & ++++ & +++ & ++++ & ++++ & ++ & + & + & + & +++ \\
\hline$\|$ & + & ++ & ++ & + & + & + & + & + & ++ \\
\hline III & +++ & ++ & ++++ & ++ & + & + & ++ & + & +++ \\
\hline V & ++++ & +++ & ++++ & +++ & +++ & ++++ & +++ & +++ & ++++ \\
\hline VI & ++++ & +++ & ++++ & +++ & ++++ & ++++ & +++ & +++ & ++++ \\
\hline \multicolumn{10}{|l|}{ PL } \\
\hline I & ++++ & ++++ & +++ & +++ & +++ & +++ & +++ & ++ & + \\
\hline$\|$ & ++ & ++ & ++ & ++ & + & +++ & + & + & +++ \\
\hline III & ++ & +++ & ++ & +++ & +++ & +++ & ++ & + & +++ \\
\hline V & +++ & ++++ & ++++ & +++ & ++++ & ++++ & +++ & ++ & ++++ \\
\hline VI & ++ & ++++ & ++++ & +++ & +++ & ++++ & +++ & +++ & ++++ \\
\hline \multicolumn{10}{|l|}{ IL } \\
\hline I & ++++ & ++++ & ++ & ++++ & ++ & + & + & + & + \\
\hline II & ++ & ++ & ++ & ++ & + & + & + & + & ++ \\
\hline III & ++ & +++ & ++ & ++ & ++ & + & + & + & ++ \\
\hline V & +++ & ++++ & ++++ & ++++ & +++ & +++ & ++ & + & +++ \\
\hline VI & +++ & ++++ & ++++ & +++ & ++ & ++++ & +++ & +++ & ++++ \\
\hline
\end{tabular}

eYFP-positive fibers were estimated for every layer and subdivision, ranging from + for a low number of eYFP-positive fibers to ++++ for a high number of eYFP-positive fibers.

forebrain. These mapping distributions were gradual, and all mice had sparser eYFP-positive fiber innervations in the MPFC subdivisions that were not preferentially innervated. (4) There is layer specificity in the projections from the rostral versus caudal regions of the basal forebrain. The mice in which injections had produced labeled axons in the medial pathways also showed a strong innervation of superficial layers in IL, PL, and ACv, suggesting that cholinergic fibers arrive via different routes in the superficial and deep layers in the $\mathrm{mPFC}$ regions.

Previous work has studied the topographic mapping of the cholinergic system using a combination of retrograde tracing with post hoc immunohistochemical identification (Bigl et al., 1982; Price and Stern, 1983; Zaborszky et al., 1986, 1999; Gritti et al., 1997, 2003). Although these studies have provided a wealth of knowledge and have demonstrated a mapping of neurons in the basal forebrain to discrete regions in the cortex, they have mainly focused on the innervation of large cortical areas that were located far apart. Recently, the same approach has been used to study projections to different regions within the PFC (Chandler and Waterhouse, 2012; Chandler et al., 2013; Zaborszky et al., 2013). This work suggested that there is much overlap between the innervation to different $\mathrm{mPFC}$ regions. After injection of retrograde tracers in the anterior cingulate cortex, $\mathrm{mPFC}$, and orbitofrontal cortex, it was found that $\sim 60 \%$ of the basal forebrain neurons target more than one of these areas and that $20 \%$ of the neurons innervates all three areas. No relation was found with the rostrocaudal location in the basal forebrain. This discrepancy with our findings could be the result of species differences. However, in our opinion, it is more likely a consequence of the difference between retrograde and anterograde tracing approaches.
Whereas retrograde tracing studies can demonstrate that a neuron projects to a brain region, it cannot determine the density of that innervation. With our anterograde approach, it was possible to estimate the density of the axonal innervation. In a study in which an anterograde tracer was injected in the rat MCPO (Henny and Jones, 2008), it was also described that labeling was strongest in the IL, suggesting that the topographic mapping becomes evident when the density of innervation is taken into consideration. Therefore, we conclude that, although basal forebrain neurons often project to multiple regions of the PFC, they preferentially innervate different regions based on their location in the basal forebrain. Recently, it was reported that the overlap in basal forebrain innervation between two cortical regions depends on the connectivity between these regions (Zaborszky et al., 2013). Because the regions within the $\mathrm{mPFC}$ are highly interconnected (Vertes, 2004), our findings are in line with these reports.

We were able to identify and follow eYFP-positive cholinergic fibers traveling via four routes (medial, septal, internal capsule, and lateral) to their cortical termination fields. Cholinergic fibers entered cortex either via layer I (medial) route or layer VI (other routes). Interestingly, we found that injections in rostral locations of the basal forebrain show both a high number of fibers taking the medial route and a higher relative innervation of the superficial layers in the IL and PL. In these two regions, we found that caudal injections resulted in a high amount of fibers in deep layers, with a specific reduction in fibers in superficial layers. Therefore, our results suggest functional differences between the rostral and caudal parts of the basal forebrain and the pathways that innervate the $\mathrm{mPFC}$ from layer I and from layer VI. It would be interesting to test whether these differences correspond to the 


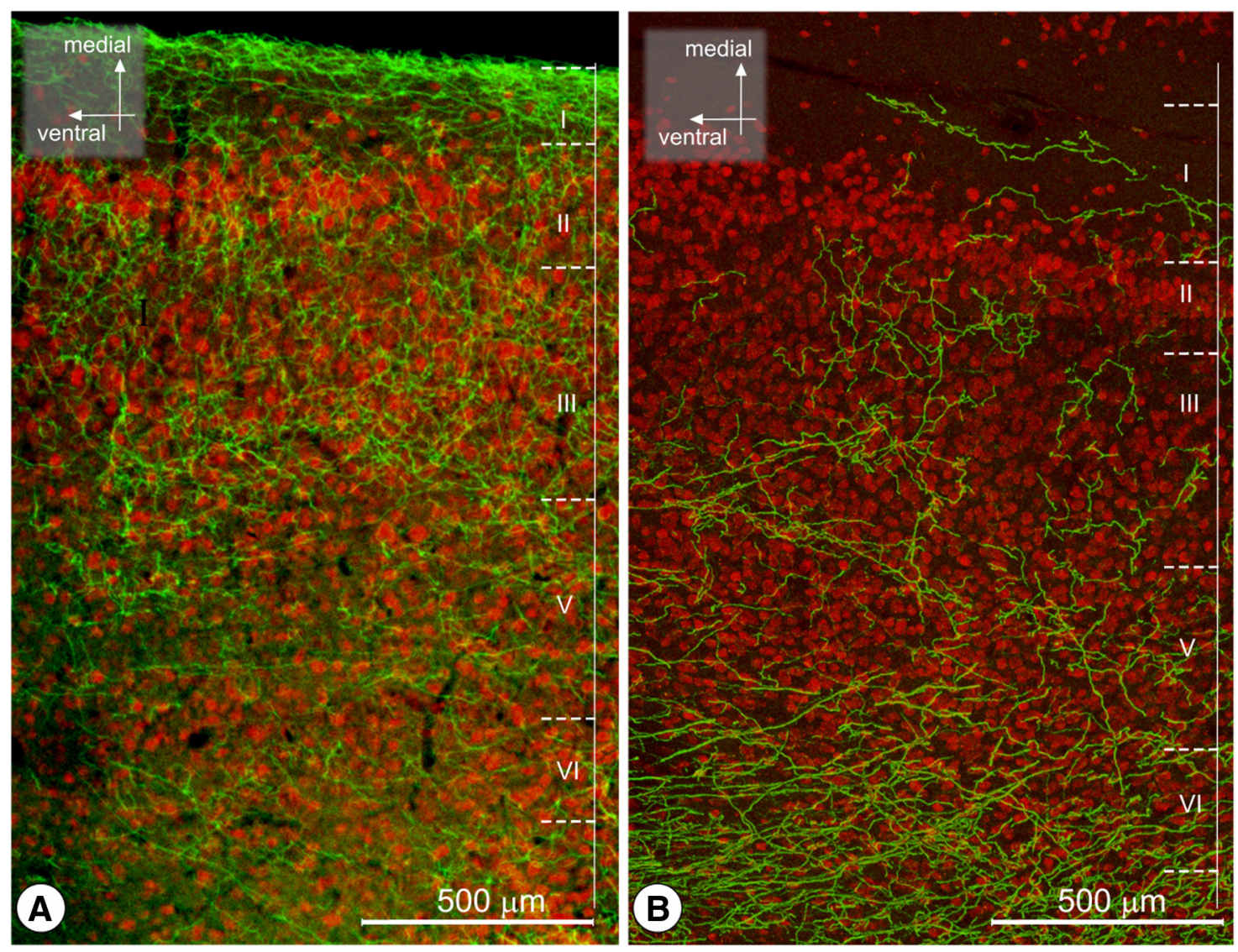

Figure 6. Layer-specific innervation by caudal and dorsal regions of the basal forebrain (Table 3). $A$, Animals with rostral injections have a cholinergic innervation throughout all layers of the IL and PL. $\boldsymbol{B}$, Animals with injections in the caudal part of the basal forebrain innervate the deep layers of these cortical areas extensively but show few fibers in the superficial layers.

two recently described electrophysiologically different populations of cholinergic neurons in the basal forebrain (Unal et al., 2012).

Although the axonal pathways leaving the basal forebrain have been shown previously in the rat brain (Saper, 1984; Luiten et al., 1987; Eckenstein et al., 1988), this is the first ChAT-specific anterograde tracing study and the first in the mouse brain (although visualizations of ChAT fibers in ChAT-Cre mice are available in the Allen Brain Atlas; http://www.brain-map.org/). Moreover, we provide novel information about the relation between the location of basal forebrain neurons, the routes of their axons, and their regional and laminar targets in the mPFC. After entering the cortex, the cholinergic fibers branch off collaterals that run radially and supply a dense network of varicose to hypervaricose (layer I) fibers with a rather uniform fiber thickness, as was found in rat Fr1 and the somatosensory cortex (Mechawar et al., 2000). The far majority of the varicosities on the "parallel" fibers and their collaterals are present in an en passant arrangement.

The total length of cortical and PFC cholinergic fibers has been estimated in rats (Mechawar et al., 2000). In mice, the total length of neocortical cholinergic fibers has been estimated previously using AChE immunohistochemistry and stereological analysis (Boncristiano et al., 2002). We provide here a quantification of cholinergic fiber lengths for different mPFC areas per hemisphere that originate in specific parts of the basal forebrain.

We found differences in the number of transfected neurons for the different injection sites. We believe that this is primarily attributable to differences in the density of cholinergic neurons throughout the basal forebrain (Zaborszky et al., 1999). Poten- tially, it could reflect an uneven spread of the virus through the tissue but, to our knowledge, very little is known about this. Importantly, the animals were genetically identical and had the same age, and the virus was made in one batch and was always subjected to the same number of freeze-thaw cycles excluding the possibility that these factors cause differences in viral uptake or expression rates.

The ChAT-Cre recombinant mouse is an excellent model to study cholinergic projections in detail. Focal viral microinjections induced eYFP expression in selected neurons, restricted to the injection location. We verified using ChAT immunofluorescence histochemistry that all eYFP-positive cell bodies were ChAT positive, and we therefore consider all eYFP-positive fibers to be cholinergic. The accumulation of eYFP in fibers was sufficiently high to enable us to trace fibers along various pathways to their cortical destinations. An advantage of the Cre-Lox/viral expression system was that there was only eYFP production at the injection loci, whereas the cholinergic prefrontal cortical interneurons and their fibers remained unaffected and therefore were literally "left in the dark" (Dautan et al., 2014). Thus, our study dealt exclusively with basal forebrain innervation of mPFC with the exclusion of local cholinergic fibers as well as fibers originating from the pedunculopontine nucleus and laterodorsal tegmental area. A third advantage of the use of the Cre-Lox recombination technique compared with classical neuroanatomical tracing is the pertinent absence of retrograde transport of the tracer. Areas that are known to project to the basal forebrain cholinergic neurons, e.g., hypothalamic nuclei that project to VDB and HDB (Swanson and Cowan, 1979), were free of any sign of retrograde transport. Be- 
cause the amygdala is a strong source of input to NB (Swanson and Cowan, 1979), we looked specifically for retrograde transport here. Although densely innervated by eYFP-positive fibers (an extremely dense innervation of the basal amygdaloid nucleus was present in mouse 6 in which virus had been injected in NB), we did not observe any eYFP-positive neurons in any of our experiments in any of the amygdaloid nuclei. We consider the few eYFP-positive neurons in the striatum as resulting from injection track labeling rather than retrograde transport because these eYFP-positive neurons were only present along the dorsoventrally oriented injection tracks.

In this study, the regional cholinergic innervation of the $\mathrm{mPFC}$ and the topographic relation with the basal forebrain were investigated. For understanding how ACh influences information processing in the mPFC, it is crucially important to know the ACh receptor distribution in this brain structure. To our knowledge, no study specifically looked into regional differences of ACh receptors between the $\mathrm{mPFC}$ areas, but based on work comparing other cortical areas (Gulledge et al., 2007) and autoradiographical studies (Clarke et al., 1984; Spencer et al., 1986), the differences in ACh receptors throughout cortical areas seem relatively small. Concerning cortical layers, the picture is very different. Electrophysiological recordings in acute brain slices have demonstrated a marked layer specificity in the responses to ACh (Christophe et al., 2002; Couey et al., 2007; Kassam et al., 2008; Arroyo et al., 2012; Poorthuis et al., 2013). Our data suggest that different layers also receive acetylcholine from different neuronal populations in the basal forebrain. It will be of great interest to test whether the different innervations of the mPFC are related to specific cholinergic signaling modes (Sarter et al., 2014). Optogenetics will be crucial in finding out how exactly the prefrontal microcircuitry is influenced by ACh release, and our data provide important considerations for researchers who want to manipulate release using methods that depend on viral transfections of cholinergic neurons. In conclusion, our data contribute to understanding the cholinergic modulation of the MPFC by providing new insights into the specificity of cholinergic innervations and the topographical relationship between the basal forebrain and their axonal projections.

\section{References}

Armstrong DM, Saper CB, Levey AI, Wainer BH, Terry RD (1983) Distribution of cholinergic neurons in rat brain: demonstrated by the immunocytochemical localization of choline acetyltransferase. J Comp Neurol 216:53-68. CrossRef Medline

Arroyo S, Bennett C, Aziz D, Brown SP, Hestrin S (2012) Prolonged disynaptic inhibition in the cortex mediated by slow, non- $\alpha 7$ nicotinic excitation of a specific subset of cortical interneurons. J Neurosci 32:3859-3864. CrossRef Medline

Bigl V, Woolf NJ, Butcher LL (1982) Cholinergic projections from the basal forebrain to frontal, parietal, temporal, occipital, and cingulate cortices: a combined fluorescent tracer and acetylcholinesterase analysis. Brain Res Bull 8:727-749. CrossRef Medline

Bolam JP, Wainer BH, Smith AD (1984) Characterization of cholinergic neurons in the rat neostriatum. A combination of choline acetyltransferase immunocytochemistry, golgi-impregnation and electron microscopy. Neuroscience 12:711-718. CrossRef Medline

Boncristiano S, Calhoun ME, Kelly PH, Pfeifer M, Bondolfi L, Stalder M, Phinney AL, Abramowski D, Sturchler-Pierrat C, Enz A, Sommer B, Staufenbiel M, Jucker M (2002) Cholinergic changes in the app23 transgenic mouse model of cerebral amyloidosis. J Neurosci 22:3234-3243. Medline

Butcher L (1995) Cholinergic neurons and networks. In: The rat nervous system (Paxinos G, ed), pp 1003-1015. San Diego: Academic.

Butcher L, Woolf N (2004) Cholinergic neurons and networks revisited. In: The rat nervous system (Paxinos G, ed), pp 1257-1268. San Diego: Academic.
Calhoun ME, Mouton PR (2001) Length measurement: new developments in neurostereology and 3d imagery. J Chem Neuroanat 21:257-265. CrossRef Medline

Chandler D, Waterhouse BD (2012) Evidence for broad versus segregated projections from cholinergic and noradrenergic nuclei to functionally and anatomically discrete subregions of prefrontal cortex. Front Behav Neurosci 6:20. CrossRef Medline

Chandler DJ, Lamperski CS, Waterhouse BD (2013) Identification and distribution of projections from monoaminergic and cholinergic nuclei to functionally differentiated subregions of prefrontal cortex. Brain Res 1522:38-58. CrossRef Medline

Christophe E, Roebuck A, Staiger JF, Lavery DJ, Charpak S, Audinat E (2002) Two types of nicotinic receptors mediate an excitation of neocortical layer i interneurons. J Neurophysiol 88:1318-1327. Medline

Clarke PBS, Pert CB, Pert A (1984) Autoradiographic distribution of nicotine receptors in rat brain. Brain Res 323:390-395. CrossRef Medline

Couey JJ, Meredith RM, Spijker S, Poorthuis RB, Smit AB, Brussaard AB, Mansvelder HD (2007) Distributed network actions by nicotine increase the threshold for spike-timing-dependent plasticity in prefrontal cortex. Neuron 54:73-87. CrossRef Medline

Cozzari C, Hartman BK (1980) Preparation of antibodies specific to choline acetyltransferase from bovine caudate nucleus and immunohistochemical localization of the enzyme. Proc Natl Acad Sci U S A 77:7453-7457. CrossRef Medline

Dalley JW, Theobald DE, Bouger P, Chudasama Y, Cardinal RN, Robbins TW (2004) Cortical cholinergic function and deficits in visual attentional performance in rats following 192 igg-saporin-induced lesions of the medial prefrontal cortex. Cereb Cortex 14:922-932. CrossRef Medline

Dautan D, Huerta-Ocampo I, Witten IB, Deisseroth K, Bolam JP, Gerdjikov T, Mena-Segovia J (2014) A major external source of cholinergic innervation of the striatum and nucleus accumbens originates in the brainstem. J Neurosci 34:4509-4518. CrossRef Medline

Eckenstein F, Baughman RW (1984) Two types of cholinergic innervation in cortex, one co-localized with vasoactive intestinal polypeptide. Nature 309:153-155. CrossRef Medline

Eckenstein F, Barde YA, Thoenen H (1981) Production of specific antibodies to choline acetyltransferase purified from pig brain. Neuroscience 6:993-1000. CrossRef Medline

Eckenstein FP, Baughman RW, Quinn J (1988) An anatomical study of cholinergic innervation in rat cerebral cortex. Neuroscience 25:457-474. CrossRef Medline

Gaykema, Luiten PG, Nyakas C, Traber J (1990) Cortical projection patterns of the medial septum-diagonal band complex. J Comp Neurol 293: 103-124. CrossRef Medline

Granon S, Faure P, Changeux JP (2003) Executive and social behaviors under nicotinic receptor regulation. Proc Natl Acad Sci U S A 100:95969601. CrossRef Medline

Gritti I, Mainville L, Mancia M, Jones BE (1997) Gabaergic and other noncholinergic basal forebrain neurons, together with cholinergic neurons, project to the mesocortex and isocortex in the rat. J Comp Neurol 383: 163-177. CrossRef Medline

Gritti I, Manns ID, Mainville L, Jones BE (2003) Parvalbumin, calbindin, or calretinin in cortically projecting and gabaergic, cholinergic, or glutamatergic basal forebrain neurons of the rat. J Comp Neurol 458:11-31. CrossRef Medline

Gulledge AT, Park SB, Kawaguchi Y, Stuart GJ (2007) Heterogeneity of phasic cholinergic signaling in neocortical neurons. J Neurophysiol 97:22152229. CrossRef Medline

Gundersen HJG, Jensen EB (1987) The efficiency of systematic sampling in stereology and its prediction. J Microsc 147:229-263. CrossRef Medline

Hasselmo ME, Sarter M (2011) Modes and models of forebrain cholinergic neuromodulation of cognition. Neuropsychopharmacology 36:52-73. CrossRef Medline

Henny P, Jones BE (2008) Projections from basal forebrain to prefrontal cortex comprise cholinergic, gabaergic and glutamatergic inputs to pyramidal cells or interneurons. Eur J Neurosci 27:654-670. CrossRef Medline

Houser CR, Crawford GD, Salvaterra PM, Vaughn JE (1985) Immunocytochemical localization of choline acetyltransferase in rat cerebral cortex: a study of cholinergic neurons and synapses. J Comp Neurol 234:17-34. CrossRef Medline

Howe WM, Berry AS, Francois J, Gilmour G, Carp JM, Tricklebank M, Lustig 
C, Sarter M (2013) Prefrontal cholinergic mechanisms instigating shifts from monitoring for cues to cue-guided performance: converging electrochemical and fmri evidence from rats and humans. J Neurosci 33: 8742-8752. CrossRef Medline

Kassam SM, Herman PM, Goodfellow NM, Alves NC, Lambe EK (2008) Developmental excitation of corticothalamic neurons by nicotinic acetylcholine receptors. J Neurosci 28:8756-8764. CrossRef Medline

Kimura H, McGeer PL, Peng F, McGeer EG (1980) Choline acetyltransferasecontaining neurons in rodent brain demonstrated by immunohistochemistry. Science 208:1057-1059. CrossRef Medline

Klinkenberg I, Sambeth A, Blokland A (2011) Acetylcholine and attention. Behav Brain Res 221:430-442. CrossRef Medline

Lanciego JL, Wouterlood FG (2011) A half century of experimental neuroanatomical tracing. J Chem Neuroanat 42:157-183. CrossRef Medline

Levey AI, Wainer BH (1982) Cross-species and intraspecies reactivities of monoclonal antibodies against choline acetyltransferase. Brain Res 234: 469-473. CrossRef Medline

Luiten PG, Gaykema RP, Traber J, Spencer DG Jr (1987) Cortical projection patterns of magnocellular basal nucleus subdivisions as revealed by anterogradely transported phaseolus vulgaris leucoagglutinin. Brain Res 413:229-250. CrossRef Medline

Mechawar N, Cozzari C, Descarries L (2000) Cholinergic innervation in adult rat cerebral cortex: a quantitative immunocytochemical description. J Comp Neurol 428:305-318. CrossRef Medline

Mouton PR, Gokhale AM, Ward NL, West MJ (2002) Stereological length estimation using spherical probes. J Microsc 206:54-64. CrossRef Medline

Mullen RJ, Buck CR, Smith AM (1992) Neun, a neuronal specific nuclear protein in vertebrates. Development 116:201-211. Medline

Parikh V, Kozak R, Martinez V, Sarter M (2007) Prefrontal acetylcholine release controls cue detection on multiple timescales. Neuron 56:141154. CrossRef Medline

Parnavelas JG, Kelly W, Franke E, Eckenstein F (1986) Cholinergic neurons and fibres in the rat visual cortex. J Neurocytol 15:329-336. CrossRef Medline

Paxinos G, Franklin K (2001) The mouse brain in stereotaxic coordinates. San Diego: Academic.

Phelps PE, Houser CR, Vaughn JE (1985) Immunocytochemical localization of choline acetyltransferase within the rat neostriatum: a correlated light and electron microscopic study of cholinergic neurons and synapses. J Comp Neurol 238:286-307. CrossRef Medline

Picciotto MR, Higley MJ, Mineur YS (2012) Acetylcholine as a neuromodulator: cholinergic signaling shapes nervous system function and behavior. Neuron 76:116-129. CrossRef Medline

Poorthuis RB, Bloem B, Schak B, Wester J, de Kock CPJ, Mansvelder HD (2013) Layer-specific modulation of the prefrontal cortex by nicotinic acetylcholine receptors. Cereb Cortex 23:148-161. CrossRef Medline

Price JL, Stern R (1983) Individual cells in the nucleus basalis-diagonal band complex have restricted axonal projections to the cerebral cortex in the rat. Brain Res 269:352-356. CrossRef Medline

Rye DB, Wainer BH, Mesulam MM, Mufson EJ, Saper CB (1984) Cortical projections arising from the basal forebrain: A study of cholinergic and noncholinergic components employing combined retrograde tracing and immunohistochemical localization of choline acetyltransferase. Neuroscience 13:627-643. CrossRef Medline

Saper CB (1984) Organization of cerebral cortical afferent systems in the rat. II. Magnocellular basal nucleus. J Comp Neurol 222:313-342. CrossRef Medline

Sarter M, Bruno JP (2000) Cortical cholinergic inputs mediating arousal, attentional processing and dreaming: differential afferent regulation of the basal forebrain by telencephalic and brainstem afferents. Neuroscience 95:933-952. Medline

Sarter M, Lustig C, Howe WM, Gritton H, Berry AS (2014) Deterministic functions of cortical acetylcholine. Eur J Neurosci 39:1912-1920. CrossRef Medline

Schmitz C, Hof PR (2005) Design-based stereology in neuroscience. Neuroscience 130:813-831. CrossRef Medline

Shiromani PJ, Armstrong DM, Bruce G, Hersh LB, Groves PM, Gillin JC (1987) Relation of pontine choline acetyltransferase immunoreactive neurons with cells which increase discharge during rem sleep. Brain Res Bull 18:447-455. CrossRef Medline

Sohal VS, Zhang F, Yizhar O, Deisseroth K (2009) Parvalbumin neurons and gamma rhythms enhance cortical circuit performance. Nature 459: 698-702. CrossRef Medline

Spencer DG Jr, Horváth E, Traber J (1986) Direct autoradiographic determination of $\mathrm{m} 1$ and $\mathrm{m} 2$ muscarinic acetylcholine receptor distribution in the rat brain: relation to cholinergic nuclei and projections. Brain Res 380:59-68. CrossRef Medline

Swanson LW, Cowan WM (1979) The connections of the septal region in the rat. J Comp Neurol 186:621-655. CrossRef Medline

Tamamaki N, Nakamura K, Furuta T, Asamoto K, Kaneko T (2000) Neurons in Golgi-stain-like images revealed by gfp-adenovirus infection in vivo. Neurosci Res 38:231-236. CrossRef Medline

Unal CT, Golowasch JP, Zaborszky L (2012) Adult mouse basal forebrain harbors two distinct cholinergic populations defined by their electrophysiology. Front Behav Neurosci 6:21. CrossRef Medline

Van De Werd HJJM, Rajkowska G, Evers P, Uylings HB (2010) Cytoarchitectonic and chemoarchitectonic characterization of the prefrontal cortical areas in the mouse. Brain Struct Funct 214:339-353. CrossRef Medline

Vertes RP (2004) Differential projections of the infralimbic and prelimbic cortex in the rat. Synapse 51:32-58. CrossRef Medline

Wallace TL, Bertrand D (2013) Importance of the nicotinic acetylcholine receptor system in the prefrontal cortex. Biochem Pharmacol 85:17131720. CrossRef Medline

Weihe E, Tao-Cheng JH, Schäfer MK, Erickson JD, Eiden LE (1996) Visualization of the vesicular acetylcholine transporter in cholinergic nerve terminals and its targeting to a specific population of small synaptic vesicles. Proc Natl Acad Sci U S A 93:3547-3552. CrossRef Medline

Wouterlood FG, Van Denderen JC, Blijleven N, Van Minnen J, Härtig W (1998) Two-laser dual-immunofluorescence confocal laser scanning microscopy using cy2- and cy5-conjugated secondary antibodies: Unequivocal detection of co-localization of neuronal markers. Brain Res Brain Res Protoc 2:149-159. CrossRef Medline

Záborszky L, Carlsen J, Brashear HR, Heimer L (1986) Cholinergic and gabaergic afferents to the olfactory bulb in the rat with special emphasis on the projection neurons in the nucleus of the horizontal limb of the diagonal band. J Comp Neurol 243:488-509. CrossRef Medline

Zaborszky L, Pang K, Somogyi J, Nadasdy Z, Kallo I (1999) The basal forebrain corticopetal system revisited. Ann N Y Acad Sci 877:339-367. CrossRef Medline

Zaborszky L, Csordas A, Mosca K, Kim J, Gielow MR, Vadasz C, Nadasdy Z (2013) Neurons in the basal forebrain project to the cortex in a complex topographic organization that reflects corticocortical connectivity patterns: an experimental study based on retrograde tracing and $3 \mathrm{~d}$ reconstruction. Cereb Cortex. Advance online publication. Retrieved October 23, 2014. doi:10.1093/cercor/bht210. CrossRef 